\title{
Coulisses
}

Revue de théâtre

15 | Hiver 1997

Varia

\section{Les clowns de la Chiffogne}

\section{Françoise Chambefort}

\section{OpenEdition}

Journals

Édition électronique

URL : http://journals.openedition.org/coulisses/4995

DOI : 10.4000/coulisses.4995

ISSN : 2546-9460

\section{Éditeur}

Presses universitaires de Franche-Comté

\section{Édition imprimée}

Date de publication : 1 janvier 1997

Pagination : 17-18

ISSN : 1150-594X

\section{Référence électronique}

Françoise Chambefort, «Les clowns de la Chiffogne », Coulisses [En ligne], 15 | Hiver 1997, mis en ligne le 26 avril 2019, consulté le 24 septembre 2020. URL : http://journals.openedition.org/coulisses/ 4995 ; DOI : https://doi.org/10.4000/coulisses.4995

Ce document a été généré automatiquement le 24 septembre 2020.

Coulisses 


\section{Les clowns de la Chiffogne}

Françoise Chambefort

\section{Le chemin de l'émotion :}

Chercher son clown... et le trouver 
1 Être clown, prendre le temps, être là tout simplement avec son corps, ses émotions, son regard, son histoire, ses petits gestes spontanés. Être là avec sa gêne, l'envie de sortir, le plaisir de jouer et d'entendre rire, faire monter l'intensité, entendre rire plus fort et puis plus rien, le silence, le moment de sortir, de rebondir, d'appeler au secours l'autre clown là, dans

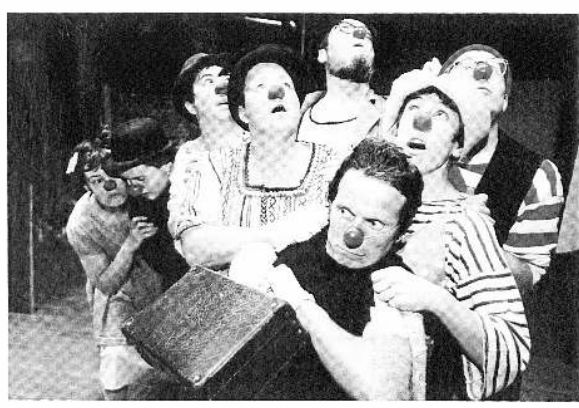
le même état prêt à tout. C'est un travail d'écoute à deux, trois, six, dix, où tout est possible; se laisser porter par le fruit de la rencontre, le savourer ensemble, oser le conflit, décider des ruptures...

2 Chercher son clown est un chemin passionnant, unique qui puise au plus profond de chacun de nous toute une richesse, pas toujours belle et gentille, qu'il n'est pas facile de montrer. Chemin de l'émotion vraie, des passions tendres, cruelles, bestiales ou amicales. Elles renvoient au spectateur cette part de lui-même incontournable qui même sans le savoir est là, tapie dans le noir, prête à bondir pour le meilleur comme pour le rire.

3 Rire libérateur, fou-rire à pleurer, sourire complice ou regard tendre, toute une palette à explorer sans tricher pour découvrir ce clown, le faire naître, lui donner une présence, un langage, une couleur, pour enfin le faire vivre... intensément.

\section{De l'émotion personnelle à la responsabilité collective}

\section{Les clowns de La Chiffogne \\ Qui sommes-nous?}

4 A la Chiffogne, on ne trouve pas un mais des clowns. Tous ont le même respect du spectacle et du cirque. Chacun vit intérieurement sa passion de façon différente. Le groupe rassemble une dizaine de passionnés habitant le Pays de Montbéliard, tous amateurs, au sens d'abord où ils aiment se retrouver bénévolement pour un cours de clown, un stage, une animation, un spectacle.

5 Le groupe trouve ainsi sa cohérence dans cet investissement et dans la fusion de ces différentes personnalités. Depuis quelques années ses membres ont réussi à développer sensiblement les actions de formations (cours du lundi soir pour adultes, cours du mercredi pour enfants, stages de formation, interventions en milieu scolaire) et à multiplier les animations sous différentes formes. Leurs nez rouges sont ainsi en bonne place parmi les lampions des lumières de Noël.

Ils participent chaque année à un stage de formation, animé par un professionnel. Ils ont ainsi eu l'occasion de travailler avec Alain Gautré (Ecole du Cirque de Châlon sur Marne), André Riot Sarcey (Les Nouveaux Nez), Mario Gonzalez (Atelier du Colimaçon de Strasbourg), Compagnie Embarquez, Olivier Berardi (Ecole de Cirque de Chambéry), Raymond Peyramaure (Les Oiseaux Fous), Alberto...

7 Être clown à la Chiffogne, c'est ainsi s'engager vis-à-vis des autres, prendre des responsabilités, du fait que chacun se met à nu devant les autres, de façon dynamique 
auprès d'autres structures (écoles, prisons, hôpitaux, MJC...) Le spectacle de clowns ne se vit que dans l'échange et chacun sait à la Chiffogne que tout le monde porte en lui un clown qui sommeille. 